\title{
Dynamic Tensile Strength of Lunar Rock Types
}

\author{
Stephen N. Cohn AND Thomas J. AHRens
}

Seismological Laboratory, California Institute of Technology, Pasadena, California 91125

\begin{abstract}
The dynamic tensile strengths of four rocks have been determined. A flat plate impact experiment is used to generate $\sim 1-\mu \mathrm{s}$-duration tensile stress pulses in rock samples by superposing rarefaction waves to induce fracture. A gabbroic anorthosite and a basalt were selected because they are the same rock types as occur on the lunar highlands and mare, respectively. Although these have dynamic tensile strengths which lie within the ranges 153-174 MPa and 157-179 $\mathrm{MPa}$, whereas Arkansas novaculite and Westerly granite exhibit dynamic tensile strengths of 67-88 MPa and 95-116 MPa, respectively, the effect of chemical weathering and other factors, which may affect application of the present results to the moon, have not been explicitly studied. The reported tensile strengths are based on a series of experiments on each rock where determination of incipient spallation is made by terminal microscopic examination. These data are generally consistent with previous determinations, at least one of which was for a significantly chemically altered (hydroxylated) but physically coherent rock. The tensile failure data do not bear a simple relation to compressive results and imply that any modeling involving rock fracture consider the tensile strength of igneous rocks under impulse loads distinct from the values for static tensile strength. Generally, the dynamic tensile strengths of nonporous igneous rocks range from $\sim 100$ to 180 $\mathrm{MPa}$, with the more basic, and even amphibole-bearing samples, yielding the higher values.
\end{abstract}

\section{INTRODUCTION}

Central to impact and explosive cratering processes, underground explosive excavation and fragmentation, and planetary accretion via large body interactions is the dynamic fracture behavior of rock. Experimental high velocity impact craters (submillimeter to decicentimeter radius range) produced in pristine rock and glass show that a major portion of the mass fractured by impact is in the form of plates spalled concentrically about the crater [Hörz, 1969; Vedder, 1971]. Excavation processes and consequently the final ejecta distribution and partitioning of energy strongly depend upon the brittle tensile failure characteristics of the rock, probably more so than compressional failure mechanisms. Laboratory experiments and numerical modeling show that crater evolution and ultimate shape are sensitive to the failure behavior of rocks [Quaide and Oberbeck, 1968; O'Keefe and Ahrens, 1976; Melosh, 1977].

Developing predictive capabilities in the field of explosive cratering has required examination of the dynamic fracture and fragmentation of rock [Shockey et al., 1975; Curran et al., 1977], and the possibility of in situ retorting of coal and oil shale, which requires prior rubblization, has attracted attention to its behavior under dynamic loads as well [Murri et al., 1977]. Furthermore, Matsui and Mizutani [1977] propose that the dynamic strength and deformation behavior of rocks composing planetesimal surfaces may have been important in controlling accretion of planetesimals in the early stages of planetary formation.

Most studies of the strength of rock have been in the quasistatic regime of hydraulic or mechanical press experiments with strain rates as low as $10^{-8}$ per second ranging up to $3 \times$ $10^{3}$ per second obtainable with Hopkinson-bar apparatuses. The tensile fracture strength of rock exhibits very little dependence on strain rate at rates below $10^{3}$ per second but increases dramatically at the higher strain rates produced by shock waves in explosion, impact, and the highest strain rate Hopkinson-bar experiments [Rinehart, 1965; Stevens, 1974; Kumar, 1968; Grady and Hollenbach, 1977]. Quasi-static ten-

\footnotetext{
Copyright (-) 1981 by the American Geophysical Union.
}

sile tests, such as employing the Brazilian geometry, demonstrate a stronger dependence on specimen size and geometry than strain rate [e.g., Price and Knill, 1967]. Care must be exercised in comparing fracture strength values over the range of strain rates, since the low strain rate experiments all maintain uniaxial stress states, in the test material, while the shock wave techniques produce uniaxial strain. Nevertheless, Kumar's examination of temperature effects upon the compressive fracture strength of rock suggests that a thermal activation process dominates at low strain rates, but inertial and frictional shearing controlled failure appear to dominate failure processes at strain rates between $10^{3}$ and $10^{4}$ per second [Janach, 1976]. Grady and Lipkin [1980] have examined a series of tensile failure models and point out several previous models and a wide class of data suggesting that tensile fracture strength is proportional to the cube root of strain rate. However, sufficient data on the behavior of various brittle materials, under high rate loading, are lacking.

In this study we have selected two basic igneous rocks, a basalt and a gabbroic anorthosite, because these are the same rock types as occur on the lunar mare and highlands, for determination of dynamic tensile fracture strength. Two other rocks, Arkansas novaculite and Westerly granite, were also tested for comparison with previous studies and different techniques. At a strain rate between $10^{4}$ and $10^{5}$ per second the rock samples are subjected to $1-\mu s$-duration tensile stress pulses in a flat plate impact experiment. The stress level is varied to determine the stress which produces fracture initiation and growth. This is detected by microscopic examination for incipient spall cracks in polished thin sections made from the recovered samples. While such an approach does not determine the strain rate dependence, the conditions of fracture are appropriate for cratering and other dynamic tensile fracturing processes.

\section{EXPERIMENTAL DESIGN}

A dynamic tensile stress pulse is produced by superposing, along the midplane of the study sample, two converging planar rarefaction waves, each originating from a free surface reflection of a compressive wave [Shockey et al., 1973; Curran et al., 1973]. Protected recovery of the free-flying rock target, 


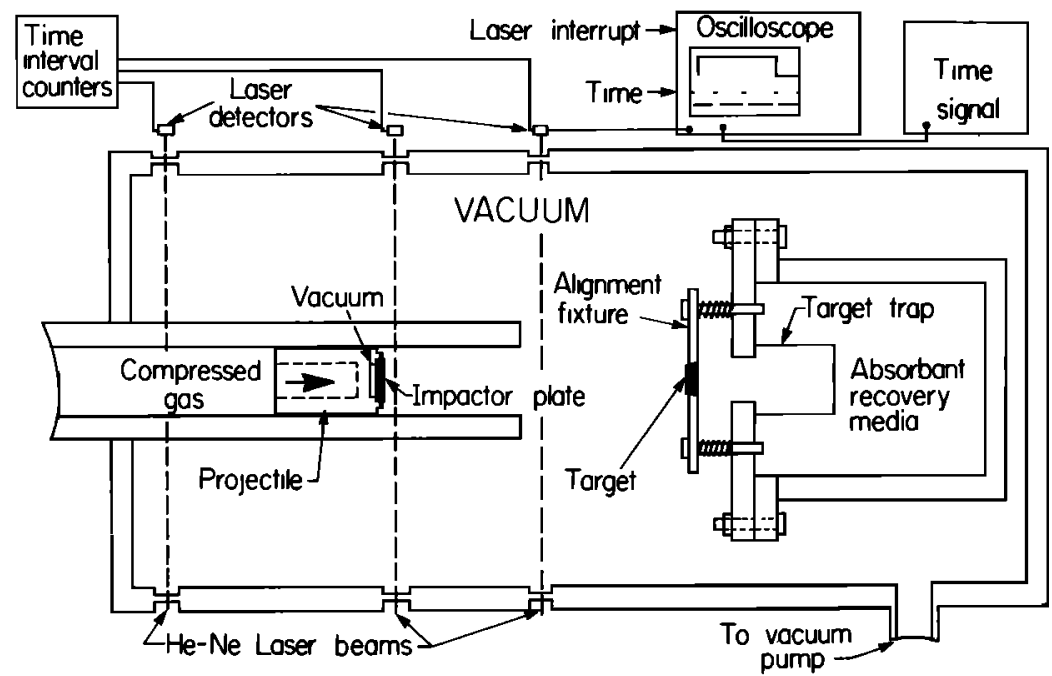

Fig. 1. Sketch of muzzle area of gas gun showing recovery tank, sample holder, and alignment fixture. The velocity of the projectile is determined both by the travel time between laser beams and by the duration of the interruption of the third beam by the projectile. After impact the sample breaks its supports and flies freely into the target trap, where it is protected from further damage.

after the initial impact, allows it to be sectioned and microscopically examined.

The experimental system (Figure 1) utilizes a 40 -mm bore powder gun fitted, for these experiments, with a compressed gas breech firing system which provides velocity control in the desired range of 10 to $90 \mathrm{~m} / \mathrm{s}$. This produces tensile stresses between 27 and $243 \mathrm{MPa}$ ( 0.27 to $2.43 \mathrm{kbar}$ ). The 75 -g projectile, machined from polycarbonate, fits in the barrel without $O$ rings or other seals to resist motion. Resting in the barrel during evacuation to $100 \mu \mathrm{m} \mathrm{Hg}$, it is retained by a strand of fine magnet wire which breaks when the stored charge of compressed air is dumped through the breech.
The impact plate is mounted on the front of the projectile. Polymethylmethacrylate (PMMA) sheet stock is used for the impact plate material in these experiments, since it has a low shock impedence [Barker and Hollenbach, 1970]. The impact plate is press fitted into the projectile so that it is supported circumferentially, making its rear face a free surface.

Tension is produced in the rock target by superposing two converging, planar rarefaction waves in a uniaxial strain configuration (Figure 2). The initial impact between the impact plate and the rock target produces compressional shock waves propagating away from the plane of contact into each medium, putting both into uniaxial compression. The wave trav-

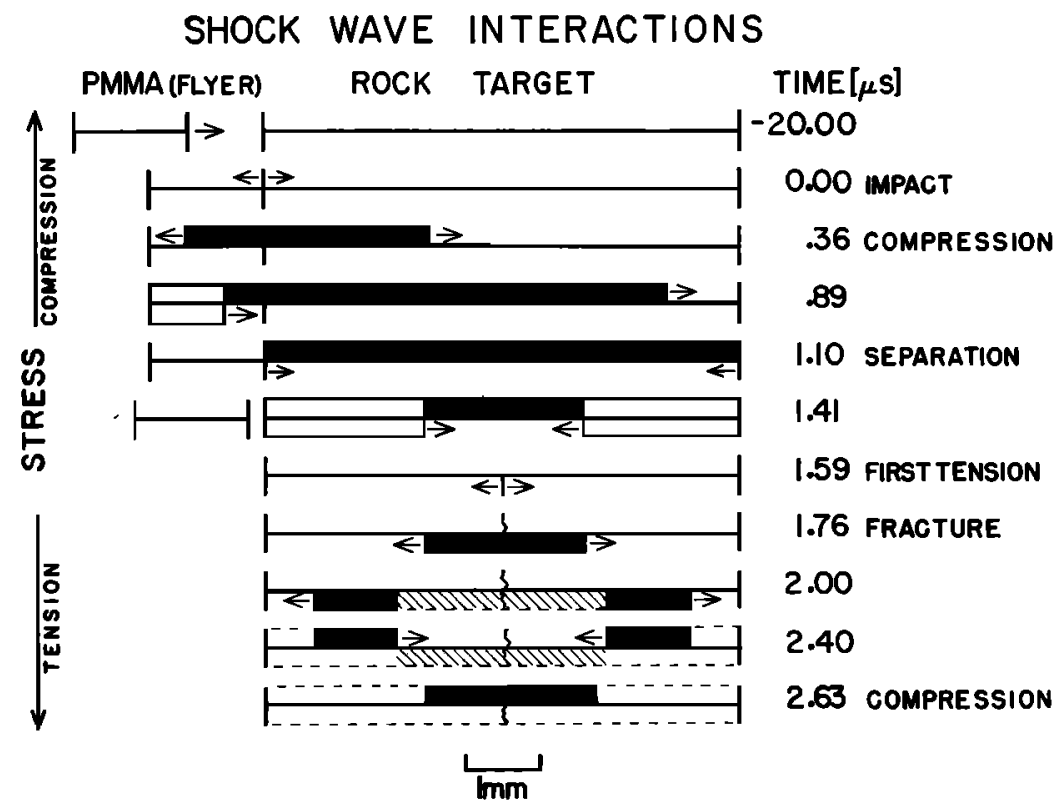

Fig. 2. Diagrammatic representation of sequence of 11 states produced upon interaction of shock waves developed at impact. In the diagram encompassing both target and impactor the vertical direction represents stress. Initial compressional waves propagate away from the impact plane, are reflected from the free surfaces of the target and impactor plate, and then superpose in the middle of the target to create uniaxial extension with $\sim 1-\mu s$ duration. The timing of the events depicted depends on the wave velocity and thickness of the target and impactor plate, while the stress level is controlled by the material impedances and impact velocity. 
eling into the impact plate reflects off of the free rear surface as a relief wave and propagates back to the contact plane, reducing the stress in the plate to zero. The geometry, in each experiment, is chosen so that the impact plate relief wave reaches the contact plane, reducing the stress to zero at the same time that the forward propagating wave in the target reflects from the target's free surface as a relief wave; this corresponds to the fifth state depicted in Figure 2. The two rarefaction waves propagating in from the surfaces of the target drop the stress in the target to zero, but each wave is accelerating material away from the plane of potential tensile failure so that when they meet, they superpose to produce tension, shown in the seventh state, $1.59 \mu$ s after impact. The figure depicts two cases. If no fracture occurs, then the two waves propagate to the sample's surfaces, bringing the whole target into tension; this is shown by the dashed lines. The two waves each reflect from the free surfaces as compressive waves and propagate to the midplane, dropping the stress to zero in their path, and superpose in the middle to produce compression, beginning a new cycle. This cycle repeats until the energy is dissipated. The midplane of the target is held in tension for at most $\sim 1 \mu \mathrm{s}$ between states 7 and 11. This interval is controlled only by the velocities of propagation and the thickness of the target and impact plate; it can be increased by using proportionally thicker elements.

In the case where fracture does occur, the free surface created by the fracture radiates a compression wave which drops the stress in the target to zero as it propagates away from the fracture surface. This is depicted in Figure 2 by ignoring the dotted lines and hatching. If fracture is induced in the target, the period of tension is reduced to the time interval between initial tension and the development of the fracture so that in practice, while unfractured samples experience $\sim 1-\mu \mathrm{s}$ intervals in tension, samples which do fracture are held in tension for shorter periods of time.

The rock target is machined to approximately 20 -mm diameter and 6-mm thickness with parallel faces, one slightly beveled to aid identification in thin section. The target is then finished on a surface grinder and hand-lapped to within $5 \mu \mathrm{m}$ of flatness across the face. Using a brittle wax tooling compound, it is suspended in a loose-fitting annulus so that its impact surface projects forward slightly. The mounting annulus and target are then fastened to the recovery vessel by three springloaded alignment screws. The impact surface of the target is oriented normal to the axis of the barrel by reflecting an axial laser beam back down the barrel. The impact plate on the projectile is also carefully fitted normal to the axis of the projectile to insure planar impact.

The target assembly is positioned in front of an aperture in the recovery vessel, as shown in Figure 1 . This permits the rock sample to fly freely into the recovery vessel after snapping its wax supports upon impact but prevents the larger-diameter projectile from following. The target, or target picces if fragmentation occurs, collects in a cloth sack which seals as it flies free of its support. The sack and enclosed rock target are decelerated and cushioned by loosely stuffed rags and foam rubber in the recovery chamber.

During the experiment, only the impact velocity of the projectile is recorded, from which the dynamic stress may be calculated, as described below. The velocity of the projectile

TABLE 1. Properties of Rocks

\begin{tabular}{|c|c|c|c|c|c|c|c|}
\hline Rock & $\begin{array}{l}\text { Minerology, } \\
\text { \% by volume }\end{array}$ & $\begin{array}{c}\text { Grain } \\
\text { Size, mm }\end{array}$ & Texture & $\begin{array}{c}\text { Flaw } \\
\text { Structure }\end{array}$ & $\begin{array}{c}\text { Density, } \\
\mathrm{g} / \mathrm{cm}^{3}\end{array}$ & $\begin{array}{l}\text { Ultrasonic } \\
\text { P Velocity, } \\
\text { km/s }\end{array}$ & $\begin{array}{c}K, \text { PMMA } \\
\text { Impact } \\
\text { Plate, } \\
10^{6} \mathrm{~kg} / \mathrm{m}^{2} / \mathrm{s}\end{array}$ \\
\hline $\begin{array}{l}\text { Arkansas } \\
\text { novaculite }\end{array}$ & $100 \%$ quartz & 0.01 & $\begin{array}{l}\text { equigranular, } \\
\text { occasional } \\
100-\mu \mathrm{m} \text { fragments }\end{array}$ & $\begin{array}{l}\text { oriented } \\
\text { cracks } \\
\text { up to } 0.5 \mathrm{~mm} \\
\text { [Shockey et al., } \\
\text { 1974] }\end{array}$ & $2.6^{*}$ & $6.0^{*}$ & 2.7 \\
\hline $\begin{array}{c}\text { Westerly } \\
\text { granite }\end{array}$ & $\begin{array}{l}37 \% \mathrm{~K} \text { feldspar } \\
30 \% \text { plagioclase } \\
\text { (An 10-20) } \\
26 \% \text { quartz } \\
6 \% \text { mica } \\
1 \% \text { opaques }\end{array}$ & $\begin{array}{l}0.1-0.8 \\
0.2-1.0 \\
0.2-0.6\end{array}$ & $\begin{array}{l}\text { equigranular } \\
\text { subhedral }\end{array}$ & $\begin{array}{l}\text { craciks up to } \\
0.3 \mathrm{~mm} \\
\text { [Hadley, 1976] }\end{array}$ & $2.6^{*}$ & $5.0^{*}$ & 2.6 \\
\hline $\begin{array}{l}\text { Beaver Bay } \\
\text { gabbroic } \\
\text { anorthosite }\end{array}$ & $\begin{array}{l}\text { 67\% plagioclase } \\
\text { (An 60-90) } \\
26 \% \text { pyroxene } \\
5 \% \text { opaques } \\
2 \% \text { limonite }\end{array}$ & $\begin{array}{l}0.4-0.7 \\
0.1-0.7\end{array}$ & $\begin{array}{l}\text { intergranular, } \\
\text { euhedral equigranular } \\
\text { subhedral }\end{array}$ & & $3.0 \dagger$ & $6.8 \dagger$ & 2.8 \\
\hline Ralston basalt & $\begin{array}{l}\text { 63\% feldspar } \\
\text { 15\% plagioclase } \\
\text { (An 70-90) } \\
15 \% \text { pyroxene } \\
\text { (augite) } \\
5 \% \text { opaques } \\
2 \% \text { limonite }\end{array}$ & $\begin{array}{l}<0.1 \\
0.7-1.2 \\
1-1.5\end{array}$ & $\begin{array}{l}\text { fine grained feldspar } \\
\text { matrix } \\
\text { euhedral phenocrysts } \\
\text { euhedral phenocrysts }\end{array}$ & & $2.8 \dagger$ & $6.4 \dagger$ & 2.8 \\
\hline
\end{tabular}

The modal fractions, from Rosiwal analysis, are approximate.

* Grady and Hollenbach [1978].

†This study. 
prior to impact is determined by the sequential interruption of three laser beams, one at the muzzle and two which traverse the barrel (Figure 1), during the final $40 \mathrm{~cm}$ of projectile travel. Each beam is monitored by a photodiode detector that triggers a time interval counter which is halted when the next beam is interrupted. The counters provide an accuracy of \pm 10 $\mu \mathrm{s}$, and beam spacing is measured to $\pm 0.5 \mathrm{~mm}$, resulting in an overall precision of $\pm 0.5 \%$ for average interval velocities $[A h$ rens et al., 1971]; however, over the velocity range of 10 to 90 $\mathrm{m} / \mathrm{s}$ the projectile is still accelerating as it approaches the muzzle of the barrel so that increases of $20 \%$ were not uncommon between the first and second average interval velocities. We relied instead on the velocity of the projectile as it leaves the barrel, which was measured by recording, on a dual-trace oscilloscope, the signal from the third laser detector with a calibrated $10-\mathrm{kHz}$ time signal on the second trace. The velocity is then determined from the length of the projectile and the time interval that the laser beam is blocked. Measuring the interrupt time from the photographic record of the oscilloscope trace is the principal limit on accuracy. The overall accuracy varied from $\pm 1 \%$ to $\pm 4 \%$ depending how close the actual velocity is to the predicted velocity and hence whether the signal occupies most of the oscilloscope sweep.

To maintain a state of uniaxial strain in the target samples during the tensile pulse, the sample must have a sufficiently large diameter that relief waves from the edges do not propagate into the region of interest. As the tensile state ends, at each point, after the shock wave has traversed at most twice the thickness of the sample beyond that point, the minimum diameter to assure strictly uniaxial strain in the center of the target is 4 times the thickness. In this experiment the target must be smaller than the projectile to allow recovery so that in practice, a ratio of 3 to 1 is employed. Consequently, relief waves from the initial compressional phase will reach the center of the target during the tensile phase, shifting the dynamic stress state somewhat by increasing the tension acting on planes normal to the impact plane and increasing the axial stress level approximately $15 \%$, but the greatest principal stress will still act normal to the impact plane. Our calculations of stress levels assume uniaxial strain, ignoring this effect.

Induced tensile spall fractures are expected to lie normal to the axis of greatest principal tension and will therefore be parallel to the impact face. In this experiment the strain rate and length of time at tension are held essentially fixed while the stress level is varied by varying the impact velocity; thus it is the stress level at which crack growth is initiated, under dynamic loading, that is determined.

\section{DYNamic Stress LeVel}

The intensity of the tensile stress created by combining the two relief waves in the target is a function only of the densities and wave velocities of the target and impact plate, and of the impact velocity. We have assumed that the relief waves travel at the same velocity as the compression waves and that attenuation of the stress waves is low so that the magnitude of the

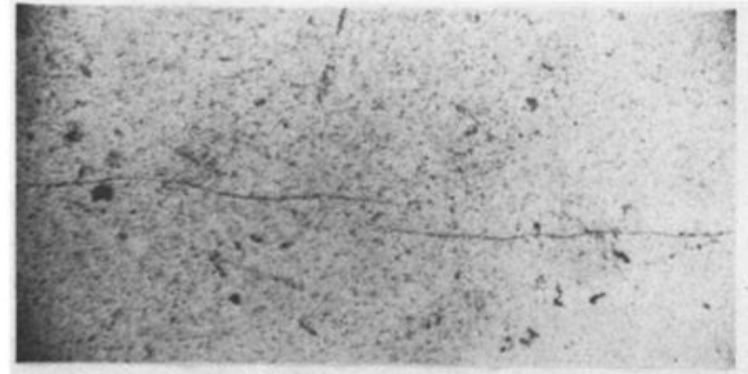

(a) ARKANSAS NOVACULITE

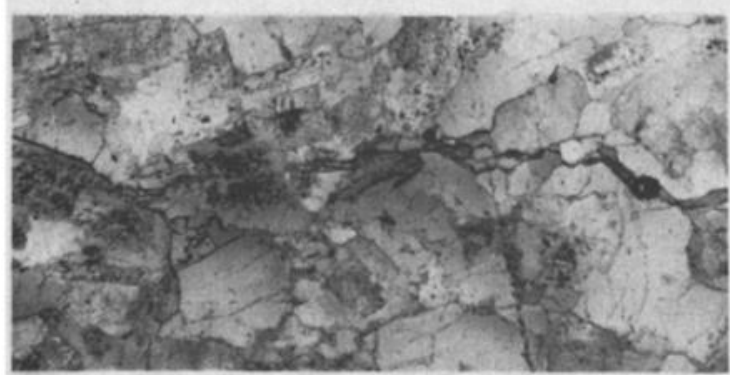

(C) WESTERLY GRANITE
$85 \mathrm{MPa}$

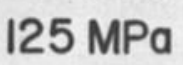

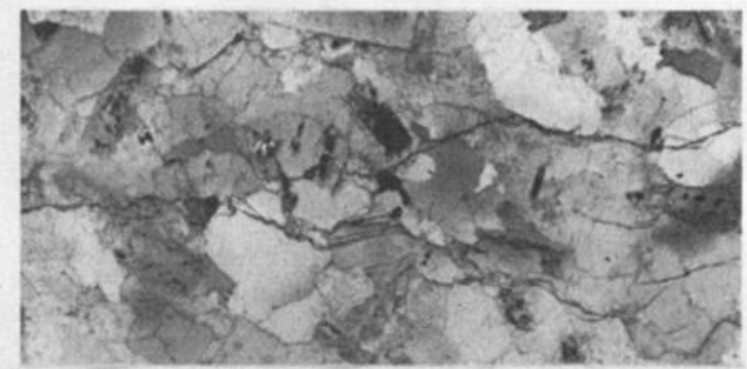
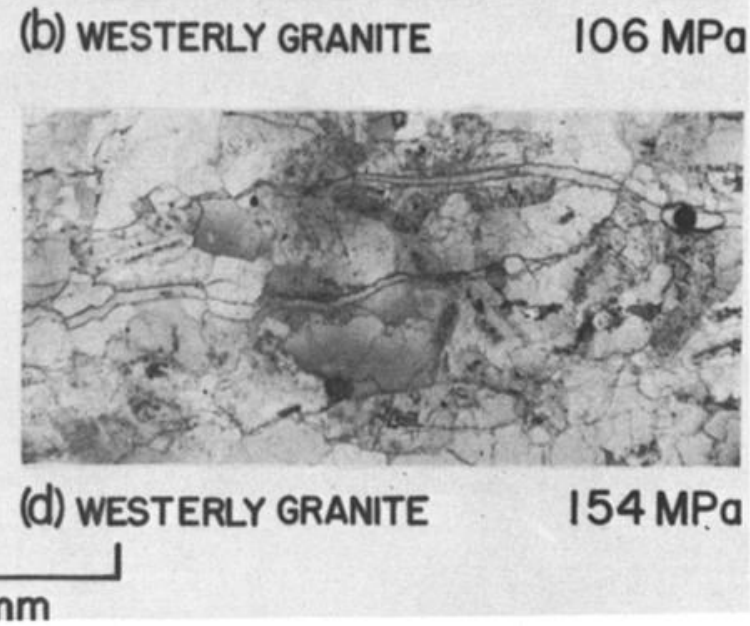

Fig. 3. (a) Reflected light photomicrograph of overlap of two adjacent induced cracks in Arkansas novaculite in a sample which showed 11 2- to 4-mm cracks running entirely across both cross sections. $(b-d)$ Westerly granite targets stressed at increasing levels to demonstrate fracturing, indicating that the dynamic tensile strength is exceeded (Figures $3 b$ and $3 c$ ), and the widening and fracturing on multiple planes and fragmentation that develops at higher stresses Figure $3 d$. The impact plane is parallel to the long dimension in each image. 
tensional stress developed equals the compressional stress level in the first phase of compression.

The level of compressional stress is governed by the familiar momentum and stress equations. Let us define the following parameters:

$\rho_{b} \rho_{t}$ respective initial state densities of the impact and target materials;

$u_{i} u_{t}$ respective particle velocities, after passage of initial shock waves, relative to the laboratory;

$c_{b} c_{t}$ respective longitudinal $(P)$ wave velocities of impact and target materials;

$\sigma_{t}, \sigma_{t}$ principal stress component acting normal to plane parallel to impact surface, for impact plate and target;

$U_{p}$ impact velocity of the projectile.

Then the momentum equation, applied both to target and impact plate, becomes

$$
\sigma_{t}=\rho_{t} c_{t} u_{t} \quad \sigma_{i}=\rho_{t} c_{i}\left(U_{p}-u_{i}\right)
$$

At the impact plane we have continuity of both displacement and stress, yielding

$$
\begin{aligned}
& u_{t}=u_{i} \quad \sigma_{t}=\sigma_{i} \\
& \sigma_{t}=\rho_{i} c_{i}\left(U_{p}-\frac{\sigma_{t}}{\rho_{t} c_{t}}\right)
\end{aligned}
$$

and

$$
\sigma_{t}=\frac{\rho_{t} c_{t} \rho_{1} c_{i}}{\rho_{c_{i}}+\rho_{c_{t}}} U_{p}=K U_{p}
$$

which relates the stress level, in the target, to known quantities.

The impact plate material, PMMA, has been extensively studied by Barker and Hollenbach [1970]. Its density is $1.18 \mathrm{~g} /$ $\mathrm{cm}^{3}$, and, in the low-stress regime relevant to this study, it has a shock wave speed of $2.8 \mathrm{~km} / \mathrm{s}$. The speed of rarefaction waves exceeds that of the compressional waves by no more than 5\%, at these stress levels, and this difference is ignored. As only the impact velocity is measured during the experiment, the actual shock wave velocities in the target and impact plate, for each experiment, are unknown. However, the measured variation of shock wave velocity with stress level is small in PMMA over the range of interest. While rock materials show substantial increases in longitudinal velocity under uniaxial stress conditions between stresses of zero and $50 \mathrm{MPa}$ [Tocher, 1957], it is shown below that these variations are not important to the determination of stress levels. For the rock samples it is assumed that the shock wave velocity is equal to the ultrasonic longitudinal velocity measured in this study. We also assume that the elastic moduli and consequently the propagation velocity do not change significantly as the rock goes from compression to extension. Failure of this assumption would imply that the tensile stress produced is different from the compressive stress which is determined by (2). The shape of the stress wave as it propagates through the target is also unknown; however, in Grady and Hollenbach's experi-

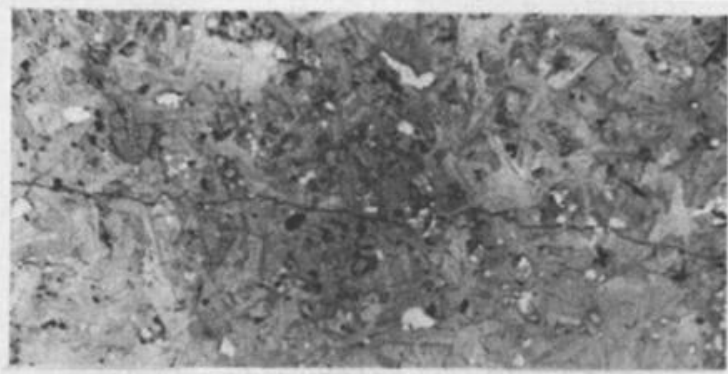

(a) GABBROIC ANORTHOSITE

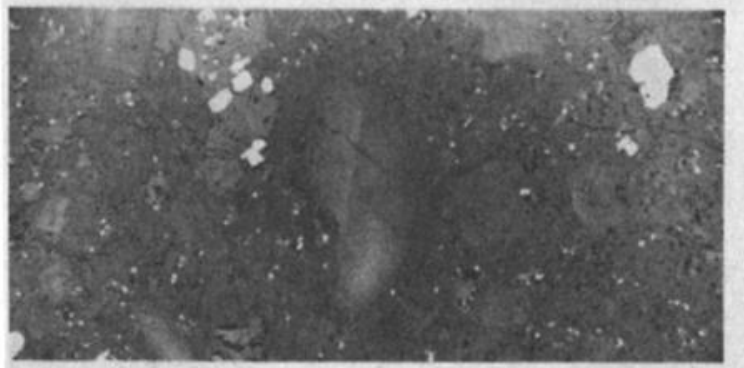

(c) RALSTON BASALT

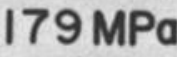

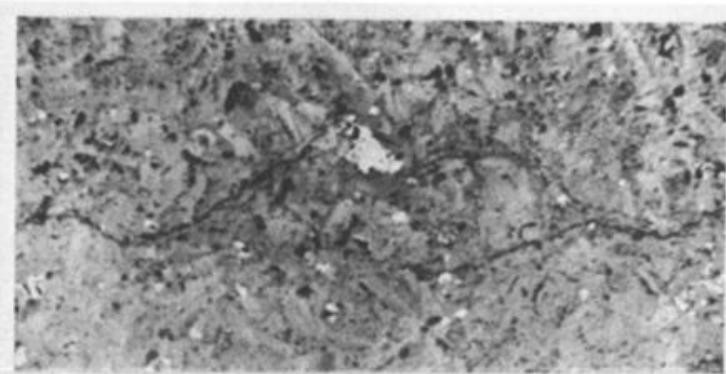
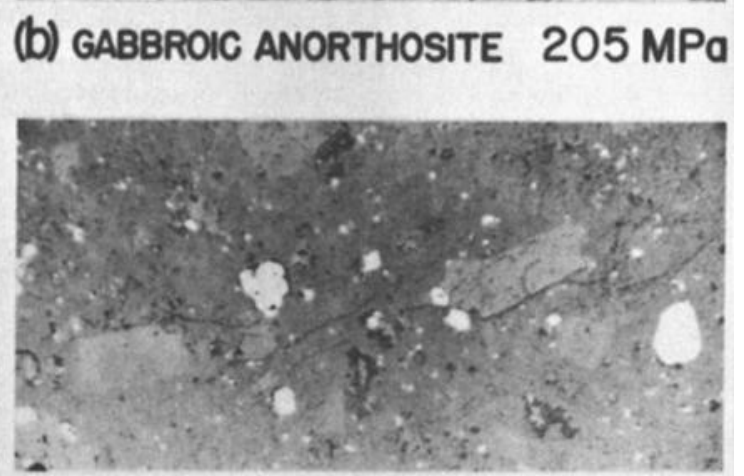

\section{(d) RALSTON BASALT}

$179 \mathrm{MPa}$

Fig. 4. (a-d) Reflected light photomicrograph of cracks in gabbroic anorthosite and Ralston basalt indicating that the dynamic tensile strength is exceeded. In each of these samples a series of cracks traverses the entire cross section close to its midplane. Propagation of fractures both through grains and along grain boundaries is illustrated by different views of the same sample of Ralston basalt (Figures $4 c$ and $4 d$ ). The impact plane is parallel to the long dimension in each image. 
TABLE 2. Record of Shots for Each Rock

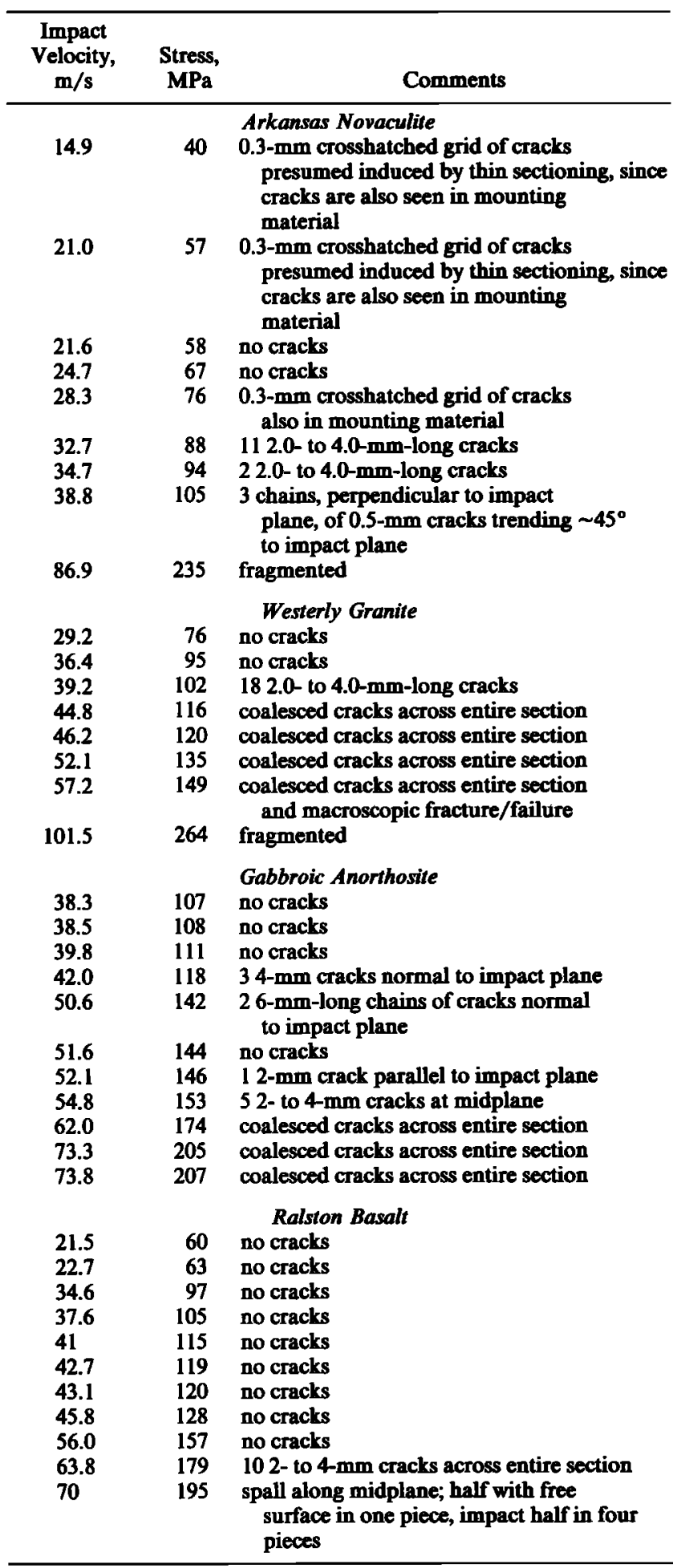

ments, where a record of free surface velocity rather than sample recovery is obtained, rise times corresponding to strain rates of $10^{4}-10^{5}$ per second are observed for rarefaction waves [Grady and Hollenbach, 1977, 1979].

While the shock wave velocities of the rocks studied are not measured, the effect of these uncertainties in $K$, the proportionality factor relating impact velocity and induced stress in
(2), is small. This is due to the low shock impedence, $I_{i}$ (product of density and wave velocity), of PMMA compared to the rocks studied. From (2) we have

$$
\frac{\partial \sigma_{t}}{\partial c_{t}} \frac{c_{s}}{\sigma_{t}}=\frac{c_{t} \partial K}{K \partial c_{t}}=\frac{I_{i}}{I_{i}+I_{t}}
$$

which relates fractional change in shock wave velocity to resulting fractional change in the value determined for stress. Substituting the values for PMMA and selected rocks (Table 1) into (3) yields

$$
\frac{\partial \sigma_{t}}{\partial c_{t}} \frac{c_{t}}{\sigma_{t}}<0.2
$$

which shows that a $10 \%$ variation in the elastic wave velocity produces less than $2 \%$ change in the value of stress determined. Thus the difference between the shock wave velocity, in a particular experiment, and the ultrasonic velocity used to calculate stress may be neglected. The values of $K$ relating stress in megapascals to projectile velocity in meters per second range between 2.6 and 2.8, shown in Table 1 for the selected rocks.

\section{LITHOLOGIES OF ROCKS}

Four competent, low-porosity rocks were selected for dynamic tensile fracturing in this study. A range of textures is explored. The most finely textured material is a $10-\mu \mathrm{m}$ grained quartzite (novaculite). The remaining three rocks have igneous origins with grain sizes ranging from $0.1 \mathrm{~mm}$ to $1.5 \mathrm{~mm}$. All samples of each lithology were made from the same piece of source rock at the same orientation. No effort has been made to examine variations in behavior due to orientation, since Shockey et al. [1973] concluded in their study of Arkansas novaculite, which shows a strong preferred flaw orientation, that dynamic strength properties are independent of orientation. One sample of each material was selected for thin sectioning to establish a baseline crack distribution for comparison to the cracks produced by the impact experiment. None of these control sections showed flaws greater than 0.5 $\mathrm{mm}$ in length, nor were any preferred orientations of the larger flaws observed which might confuse identification of induced spall cracks in a target when examined microscopically after recovery. In addition to the control samples, for each rock several tests were made at low stress levels which failed to produce spall cracks, and so the above statements apply to these sections as well, confirming the general absence of cracks which we identify as spall cracks, in unstressed samples. The distinguishing properties of each of the four rocks are given below and in Table 1 .

Novaculite, from Hot Springs, Arkansas, is a microcrystalline (10- $\mu \mathrm{m}$ grain size), homogeneous quartzite composed of uniform-sized, randomly oriented quartz grains cemented with silica. This material is transparent to a thickness of about $0.2 \mathrm{~mm}$, permitting extensive microscopic examination. Its dynamic tensile strength and fragmentation properties have been studied by Shockey et al., [1973, 1974], who also report an intrinsic, oriented system of flaws up to $1-\mathrm{mm}$ maximum diameter (sample courtesy of D. Grady).

Gabbroic anorthosite, from Beaver Bay, Minnesota, is a homogeneous, fine grained (0.2-0.7 mm) rock composed primarily of plagioclase and pyroxene. Under microscopic examination it shows only slight alteration and no porosity, cracks, or flaws, although these are assumed to exist on some scale. 
TABLE 3. Dynamic Tensile Strength and Crack Lengths

\begin{tabular}{|c|c|c|c|c|c|}
\hline \multirow[b]{2}{*}{ Rock } & \multirow{2}{*}{$\begin{array}{c}\text { Dynamic } \\
\text { Tensile } \\
\text { Strength, } \\
\mathbf{M P a}\end{array}$} & \multirow{2}{*}{$\begin{array}{c}\text { Stress, } \\
\mathbf{M P a}\end{array}$} & \multicolumn{3}{|c|}{ Crack Distribution (Full Length) } \\
\hline & & & $1.5-2.4 \mathrm{~mm}$ & $2.5-3.4 \mathrm{~mm}$ & $3.5-4.4 \mathrm{~mm}$ \\
\hline Arkansas novaculite & $67-88$ & 88 & 1 & 8 & 2 \\
\hline Westerly granite & $95-116$ & 102 & 2 & 9 & 7 \\
\hline Gabbroic anorthosite & $153-174$ & 153 & 2 & 2 & 1 \\
\hline Ralston basalt & $157-179$ & 179 & 4 & 5 & 1 \\
\hline
\end{tabular}

The dynamic tensile strength, as defined in the texh, is shown for each rock along with the stress level and distribution of cracks, by size, for the sample tested at the lowest stress level producing dynamic tensile failure.

Westerly granite, quarried in Westerly, Rhode Island, is a widely studied, medium grained $(0.1-1.0 \mathrm{~mm})$ granite primarily of feldspar and quartz. The crack density and geometry in Westerly granite are reported by Hadley [1976]. She observed no cracks greater than $0.3 \mathrm{~mm}$, with a scanning electron microscope, in unstressed samples.

Ralston basalt, quarried near Golden, Colorado [Mizutani et al., 1977], is a homogeneous, fine grained $(0.2-1.5 \mathrm{~mm})$ unweathered porphyritic basalt which shows no porosity or 0.5 to 5-mm cracks when examined microscopically (sample courtesy of H. Spetzler).

Ralston basalt and the Beaver Bay gabbroic anorthosite were chosen mainly because these are nominally the same rock types as are present on the lunar mare and highlands, respectively. Thus the behavior of the basalt and gabbroic anorthosite is expected to be representative of the pristine lunar crust under impact cratering processes. The other rocks were chosen for comparison to previous studies, some using different techniques to determine the same properties.

\section{ANALYSIS AND RESULtS}

Targets are removed from the recovery vessel in the cloth sack in which they are sealed after flying free of the mounting annulus. In general, they are intact and competent, exhibiting no visible failures at the surface, except for very highly stressed samples, which may spall into two equal pieces along their midplane or fragment. Some Arkansas novaculite samples, because of the transparency of this rock, displayed obvious internal crack surfaces. The sample disks are cut diametrically. The two halves are mounted with impact faces together and impregnated with epoxy. The cut surface is polished and mounted on a slide, and a thin section is cut and polished, resulting in two separate parallel section views of the internal fracturing of the sample.

Cracks 0.1-4 $\mathrm{mm}$ are easily delineated and photographed (Figures 3 and 4) using reflected light microscopy. In transmitted light, the high contrast between adjacent grains, particularly in the igneous rocks, enables easy identification of grain boundaries but obscures the crack traces which often follow along them. Since the cracks are generally not open, Figure $3 d$ being an exception, the accentuation due to the polishing process is necessary to see them at all.

Distinguishing possibly preexisting cracks from induced cracks is problematical, since the samples cannot be examined prior to testing. Consequently, it is assumed that every crack observed in thin section was produced by the impact experiment. This is in general untrue, since Arkansas novaculite and Westerly granite have documented natural flaws with maximum diameters less than $1 \mathrm{~mm}$ [Shockey et al., 1974; Hadley,
1976] and the Ralston basalt and gabbroic anorthosite presumably also have natural populations of flaws. Nevertheless, examination of targets recovered from low-stress shots and those never stressed show that the population of $0.5-\mathrm{mm}$ and larger cracks is low, since none were observed in 24 thin sections. In addition, induced cracks are expected to lie parallel to the impact surface, as most of those observed were found; naturally occurring cracks would not be expected to show such a preference.

The number, location, and orientation of cracks are recorded for each recovered target. Figures 3 and 4 show some examples of the observed cracks in each of the rocks studied. In each photomicrograph the impact face is parallel to the long dimension so that the observed cracks are normal to the maximum principal tension, as expected. Crack initiation and growth begin, for each rock, over a range of stress levels presumably reflecting statistical variations in the distribution of flaws from sample to sample. This effect is demonstrated in Table 2. Stress levels at or slightly above the level which pro-

TABLE 4. Comparison of Dynamic Tensile Strengths by Various Authors

\begin{tabular}{|c|c|c|}
\hline Method & $\begin{array}{c}\text { Dynamic } \\
\text { Tensile } \\
\text { Strength, } \\
\mathrm{MPa}\end{array}$ & Author \\
\hline $\begin{array}{l}\text { Free surface velocity } \\
\text { pullback signal }\end{array}$ & $\begin{array}{c}\text { Arkansas Novaculite } \\
149\end{array}$ & Stevens [1974] \\
\hline $\begin{array}{l}\text { Free surface velocity } \\
\text { pullback signal }\end{array}$ & $73-108$ & $\begin{array}{l}\text { Grady and } \\
\quad \text { Hollenbach [1979] }\end{array}$ \\
\hline Terminal examination & $38-42$ & $\begin{array}{l}\text { Shockey et al. } \\
\text { [1973] }\end{array}$ \\
\hline Terminal examination & $67-88$ & this study \\
\hline $\begin{array}{l}\text { Free surface velocity } \\
\text { pullback signal }\end{array}$ & $\begin{array}{l}\text { Westerly Granite } \\
127\end{array}$ & Stevens [1974] \\
\hline $\begin{array}{l}\text { Free surface velocity } \\
\text { pullback signal } \\
\text { Terminal examination }\end{array}$ & $\begin{array}{l}45 \\
95-116\end{array}$ & $\begin{array}{l}\text { Grady and } \\
\text { Hollenbach [1979] } \\
\text { this study }\end{array}$ \\
\hline $\begin{array}{l}\text { Free surface velocity } \\
\text { pullback signal }\end{array}$ & $\begin{array}{c}\text { Basalt (Various) } \\
114\end{array}$ & Stevens [1974] \\
\hline $\begin{array}{l}\text { Free surface velocity } \\
\text { pullback signal } \\
\text { Terminal examination }\end{array}$ & $\begin{array}{l}130 \\
157-179\end{array}$ & $\begin{array}{l}\text { Grady and } \\
\text { Hollenbach [1979] } \\
\text { this study }\end{array}$ \\
\hline
\end{tabular}

The terminal examination method is described herein. Tensile strength may also be determined by measuring the drop in velocity of the target's free surface due to the arrival of the compression wave generated by the expanding tensile crack. The technique is described by Grady and Hollenbach [1979]. 
duces crack growth cause several fractures to form. Adjacent fractures tend to terminate with slight overlap of their respective crack tips as in Figures $3 a$ and $4 b$.

We define the dynamic tensile strength to be the tensile stress which produces a chain of nearly coplanar cracks traversing the whole cross section of the target; however, this stress is less than the stress which produces strength failure, since the cracks need not coalesce. Figures $3 a-3 c$ and $4 a-4 d$ show cracks induced by dynamic tensile stresses close to the dynamic tensile strength of the particular rock. The fractures are essentially confined to one surface intersecting any traverse through the target except where adjacent crack tips overlap. Applying the above definition of dynamic tensile strength yields a range of values of stress as shown in Table 2. At the low end is the maximum stress consistently failing to produce a series of tensile cracks at the midplane of the target. At the high end is the minimum stress which repeatably produces cracks along the entire cross section. Consequently, we prefer to view the dynamic tensile strength of each of these rocks as a range of stress levels, as shown in Table 3, rather than a single value with associated error bars.

The two 'lunar' rock types exhibit the highest dynamic tensile strength of the rocks tested. Gabbroic anorthosite failed over the range 153-174 MPa, and Ralston basalt at 157-179 MPa. Westerly granite also demonstrated exceptional strength at $95-116 \mathrm{MPa}$, and Arkansas novaculite, with a dynamic tensile strength range $67-88 \mathrm{MPa}$, showed itself stronger under dynamic loads than most other sedimentary rocks [Grady and Hollenbach, 1979]. In calculations where a simple dynamic fracture strength criterion is sufficient, these values are more appropriate to describe rock behavior under shock loading than are static fracture strengths, which have often been applied but which are considerably lower.

While terminal analysis provides no direct observations of the fracturing process, it does permit us to place constraints on the crack growth velocity in the sample. Table 3 displays the distribution of cracks, tabulated according to full observed length, for the lowest stress shot, for each rock, which produced a continuous line of spall cracks at the midplane of the sample. The longest crack traces observed, in each rock, are slightly greater than $4 \mathrm{~mm}$ long. If we assume bilateral crack growth, then the maximum crack tip propagation is approximately $2 \mathrm{~mm}$, and if this occurs during the first tensile cycle, which lasts $\sim 1 \mu \mathrm{s}$, it implies an average crack velocity close to one-third the longitudinal wave velocity, which has been observed by Shockey et al. [1973].

\section{DISCUSSION}

The values for dynamic tensile strength determined by the terminal examination method of this study and Shockey et al. [1973], and by Stevens [1974] and Grady and Hollenbach [1979], using the drop in free surface velocity due to the compression waves radiating from the induced spall crack, do not agree well, as shown in Table 4. Besides disagreement in values determined by the two different techniques, which can be attributed to experimental differences, there also exist disagreements between values determined by separate studies using the same methods. Table 4 shows that these disagreements are not systematic.

It is perhaps tempting to ascribe these differences to sample variability, but more likely the inconsistency is due to the inadequate description of rock brittle failure by the single-parameter dynamic tensile strength. Nevertheless, where a simple failure criterion is desired and its imprecision is tolerable, the presently determined dynamic tensile strength provides a useful description of the dynamic failure of rock. Table 4 shows that with the exception of a single experiment on one sample, the dynamic tensile strength of nonporous igneous rocks ranges from 100 to $180 \mathrm{MPa}$, with the more basic rocks producing the higher values. We believe the greater tensile strength of basic rocks, which includes Grady and Hollenbach's [1979] Dresser basalt which contains significant quantities of amphibole, is an unexpected but significant result. The dynamic tensile strengths of igneous rocks are much higher than ever determined under quasi-static tensile conditions. The static strength of granite, for example, measured by Rhinehart [1965], is $6.8 \mathrm{MPa}$, while the dynamic values in Table 4 range between 45 and $127 \mathrm{MPa}$.

It is clear that igneous rocks, and the lunar rock types in particular, are highly resistant to short-pulse tensile stresses in the range 100-150 $\mathrm{MPa}$, much greater than the values assumed in previous crater modeling studies [O'Keefe and $A h$ rens, 1976]. The present high values of the dynamic tensile strength should be used in future efforts to model both accretion and fragmentation processes relating to the formation of solar system objects, and for impact and explosive cratering and excavation studies.

Acknowledgments. We would like to thank Raymond Jeanloz for his comments on this manuscript, Joana Vizgirda for her assistance with petrographic analysis, and Dennis Grady and Hartmut Spetzler for supplying rock samples. This work was supported under NASA grant NGL 105-002-105. Contribution 3308, Division of Geological and Planetary Sciences, California Institute of Technology, Pasadena, California 91125.

\section{REFERENCES}

Ahrens, T. J., J. H. Lower, and P. L. Lagus, Equation of state of forsterite, J. Geophys. Res., 76, 518-528, 1971.

Barker, L. M., and R. E. Hollenbach, Shock wave studies of PMMA, fused silica and sapphire, J. Appl. Phys., 41, 4208-4226, 1970.

Curran, D. R., D. A. Shockey, and L. Seaman, Dynamic fracture criteria for polycarbonate, J. Appl. Phys., 44, 4025, 1973.

Curran, D. R., D. A. Shockey, L. Seaman, and M. Austin, Mechanisms and modes of cratering in earth media, in Impact and Explosion Cratering, edited by D. J. Roddy, R. O. Pepin, and R. B. Merrill, pp. 1057-1087, Pergamon, New York, 1977.

Grady, D. E., and R. E. Hollenbach, Rate controlling processes in the brittle failure of rock, Rep. SAND 76-0659, Sandia Lab., Albuquerque, N. Mex., 1977.

Grady, D. E., and R. E. Hollenbach, Dynamic tensile fracture in rock, Rep. SAND 78-0531, Sandia Lab., Albuquerque, N. Mex., 1978.

Grady, D. E., and R. E. Hollenbach, Dynamic fracture strength of rock, Geophys. Res. Lett., 6, 73-76, 1979.

Grady, D. E., and J. Lipkin, Criteria for impulsive rock fracture, Geophys. Res. Lett., 7, 255-258, 1980.

Hadley, K., Comparison of calculated and observed crack densities and seismic velocities in Westerly granite, J. Geophys. Res., 81, 3484-3494, 1976.

Hörz, F., Structural and mineralogical evaluation of an experimentally produced crater in granite, Contrib. Mineral. Petrol., 21, 365377, 1969.

Janach, W., The role of bulking in brittle failure of rocks under rapid compression, Int. J. Rock Mech. Min. Sci. Geomech. Abstr., 13, 177186, 1976.

Kumar, A., The effect of stress rate and temperature on the strength of basalt and granite, Geophysics, 33, 501-510, 1968.

Matsui, T., and H. Mizutani, Why is a minor planet minor, Nature, 270, 506-507, 1977.

Melosh, H. J., Crater modification by gravity: A mechanical analysis of slumping, in Impact and Explosion Cratering, edited by D. J. Roddy, R. O. Pepin, and R. B. Merrill, pp. 1245-1260, Pergamon, New York, 1977. 
Mizutani, H., H. Spetzler, I. Getting, R. J. Martin III, and N. Songa, The effect of outgassing upon the closure of cracks and the strength of lunar analogues, Proc. Lunar Sci. Conf. 8th, 1235-1248, 1977.

Murri, W. J., C. Young, D. A. Shockey, R. E. Tokheim, and D. R. Curran, Determination of dynamic fracture parameters for oil shale, final report to Sandia Laboratories, Rep. PYD-5046, Stanford Res. Inst., Menlo Park, Calif., 1977.

O'Keefe, J. D., and T. J. Ahrens, Impact ejecta on the Moon, Proc. Lunar Sci. Conf. 7th, 3007-3025, 1976.

Price, D. G., and J. L. Knill, A study of the tensile strength of isotropic rocks, in Proceedings of the Ist Congress of the International Society of Rock Mechanics, vol. I, pp. 439-442, Laboratório Nacional de Engenharia Civil, Lisbon, 1967.

Quaide, W. L., and V. R. Oberbeck, Thickness determinations of the lunar surface layer from lunar impact craters, J. Geophys. Res., 73, $5247-5270,1968$.

Rinehart, J. S., Dynamic fracture strength of rocks, in Proceedings of the 7th Symposium on Rock Mechanics, vol. 1, p. 209, American Institute of Mining, Metallurgical and Petroleum Engineers, New York, 1965.

Shockey, D. A., C. F. Petersen, D. R. Curran, and J. T. Rosenberg, Failure of rocks under high rate tensile loads, in New Horizons in
Rock Mechanics, p. 709, edited by H. R. Hardy, Jr., and R. Stefanko, American Society of Civil Engineers, New York, 1973.

Shockey, D. A., D. R. Curran, L. Seaman, J. T. Rosenberg, and C. F. Petersen, Fragmentation of rock under dynamic loads, Int. J. Rock Mech. Min. Sci., 11, 303-317, 1974.

Shockey, D. A., D. R. Curran, M. Austin, and L. Seaman, Development of a capability for predicting cratering and fragmentation behavior in rock, final report, DNA 3730F, Def. Nucl. Agency, Washington, D. C., 1975.

Stevens, A. L., Spall strength of selected geological materials (abstract), Eos Trans. $A G U, 55,421,1974$.

Tocher, D., Anisotropy of rocks under simple compression, Eos Trans. $A G U, 38,89-94,1957$.

Vedder, J. F., Microcraters in glass and minerals, Earth Planet. Sci. Lett., 11, 291-296, 1971.

(Received October 4, 1979;

revised July 9, 1980;

accepted September 19, 1980.) 